\title{
On the influence of the americium isotopic vector on the cooling time of minor actinides bearing blankets in fast reactors
}

\author{
Timothée Kooyman ${ }^{*}$, Laurent Buiron, and Gerald Rimpault \\ CEA, DEN, DER, SPRC, Bat 230, Cadarache, 13108 Saint Paul lez Durance, Cedex, France
}

Received: 30 August 2017 / Received in final form: 31 January 2018 / Accepted: 20 March 2018

\begin{abstract}
In the heterogeneous minor actinides transmutation approach, the nuclei to be transmuted are loaded in dedicated targets often located at the core periphery, so that long-lived heavy nuclides are turned into shorter-lived fission products by fission. To compensate for low flux level at the core periphery, the minor actinides content in the targets is set relatively high (around 20 at.\%), which has a negative impact on the reprocessing of the targets due to their important decay heat level. After a complete analysis of the main contributors to the heat load of the irradiated targets, it is shown here that the choice of the reprocessing order of the various feeds of americium from the fuel cycle depends on the actual limit for fuel reprocessing. If reprocessing of hot targets is possible, it is more interesting to reprocess first the americium feed with a high ${ }^{243} \mathrm{Am}$ content in order to limit the total cooling time of the targets, while if reprocessing of targets is limited by their decay heat, it is more interesting to wait for an increase in the ${ }^{241} \mathrm{Am}$ content before loading the americium in the core. An optimization of the reprocessing order appears to lead to a decrease of the total cooling time by 15 years compared to a situation where all the americium feeds are mixed together when two feeds from SFR are considered with a high reprocessing limit.
\end{abstract}

\section{Introduction}

Minor actinides are three heavy nuclides created in reactors core as by-products of the chain reaction by successive captures on uranium and plutonium isotopes. Several isotopes of these elements can be found in spent nuclear fuel, namely:

$-{ }^{237} \mathrm{~Np}$ for neptunium, produced by captures on ${ }^{235} \mathrm{U}$ or $(\mathrm{n}, 2 \mathrm{n})$ reactions on ${ }^{238} \mathrm{U}$

$-{ }^{241} \mathrm{Am},{ }^{242 \mathrm{~m}} \mathrm{Am}$ and ${ }^{243} \mathrm{Am}$ for americium, produced by captures on plutonium and decay of ${ }^{241} \mathrm{Pu}$

$-{ }^{242} \mathrm{Cm},{ }^{243} \mathrm{Cm},{ }^{244} \mathrm{Cm},{ }^{245} \mathrm{Cm},{ }^{246} \mathrm{Cm}$ for curium, produced by captures on americium isotopes.

- Higher isotopes of Berkelium and Californium are rarer but some of them, such as ${ }^{252} \mathrm{Cf}$ can be dimensioning to their very high neutron source. They are mostly produced in thermal reactors loaded with MOX fuel.

In the context of a closed fuel cycle where plutonium is multi-recycled in fast reactors [1], minor actinides become the main responsible for the long-term radiotoxicity of the nuclear waste [2]. Additionally, they are generating most of the decay heat of the waste packages, which is a dimensioning parameter of final deep geological reposito-

\footnotetext{
* email: timothee.kooyman@cea.fr
}

ries [3]. However, it is possible to effectively remove the minor actinides from the waste by implementing minor actinides transmutation.

Transmutation is the process of submitting minor actinides to a neutron flux in order for them to undergo fission and then obtain shorter-lived fission products. A successful removal of all the minor actinides from the waste would reduce the long-term radiotoxicity of the spent fuel by two orders of magnitude while divide by two the volume to be excavated and save $33 \%$ in the total footprint of a deep geological repository taking into account all common infrastructures [4]

Thermal reactors are not adapted to minor actinides transmutation due to unfavorable capture to fission ratio and the necessity of a closed fuel cycle associated with transmutation, as discussed in [5]. Consequently, this paper will focus on minor actinides transmutation in fast reactors, and more specifically, sodium fast reactors. Furthermore, since complete destruction of a significant mass of minor actinides in a single irradiation is currently not achievable due to material resistance constraints (see the prohibitively long residence time discussed in [6] for instance) multirecycling of the minor actinides will be considered here.

Two main approaches can then be highlighted for transmutation in fast reactors:

- The homogeneous approach, in which minor actinides are mixed with the fuel and loaded at the core center. In this 
case, they are exposed to a high neutron flux, which increases the efficiency of the process. However, this leads to a hardening of the neutron spectrum of the core which has negative impacts on the core integral feedback coefficients [7]. Additionally, this leads to a "pollution" of the entirety of the fuel cycle plants, along with a lack of flexibility in the irradiation conditions of the minor actinides as these would depend on industrial constraints linked with fuel depletion.

- The heterogeneous approach, in which minor actinides are loaded in dedicated targets, generally located at the core periphery. In this approach, the perturbation on the core neutron spectrum is very limited and no modifications of the feedbacks coefficients can be observed. However, as the targets are located in a low-flux zone, the transmutation process is less efficient than in the homogeneous case. To compensate for this, the residence time is generally increased along with the mass loaded in the blankets. However, this has a negative impact on the decay heat of the irradiated targets, which ultimately leads to prohibitively long cooling times.

This paper will focus on the heterogeneous approach to minor actinides transmutation and especially americium heterogeneous transmutation. Indeed, ${ }^{237} \mathrm{~Np}$ has a half-life of $2.16 \times 10^{6}$ years, making it relatively harmless while americium isotopes are shorter-lived, with a half life of 7370 years for ${ }^{243} \mathrm{Am}$ and 432 years for ${ }^{241} \mathrm{Am}$, which are the main isotopes to be found in the waste. Curium is generally not considered in transmutation studies as its very high decay heat and neutron source highly complicates the manufacturing of curium-bearing fuels [8-10].

Irradiation of americium in radial blankets leads to the production of curium isotopes which have a very high neutron source and decay heat rate. Prior to reprocessing, the assemblies must be removed from the core, washed from the residual sodium and transported to a reprocessing plant. Due to technological limitations linked to the temperature of the assemblies and handling devices during all these operations, such assemblies requires longer cooling times to reach acceptable heat load before reprocessing can occur. This increases the total inventory of minor actinides in the fuel cycle (either in the core, in manufacturing or cooling down), while this inventory should be minimized in order to limit the movements of minor actinides in the fuel cycle. The dependency of the cooling time to the americium isotopic vector will be analyzed here and various strategies will be discussed to limit the cooling time of the minor actinides bearing blankets (MABB).

\section{Position of the problem and methodology}

\subsection{Analysis of the problem}

Current industrial limitations considered regarding reprocessing of MABB can be divided into two categories [11]:

- Short term handling of the assemblies for movement to external storage. Depending on the technology considered, various limitations can be taken. For a revolving drum similar to the Superphénix design, the assembly heat load can be arbitrarily high. However, if an external
Table 1. Main heat emitters in a MABB cooled for 5 years after 4100 EFPD of irradiation, with $75 \%{ }^{241} \mathrm{Am}$ and $25 \%$ of ${ }^{243} \mathrm{Am}$.

\begin{tabular}{llll}
\hline & Power in W/g & $\begin{array}{l}\text { Fraction of } \\
\text { total power }(\%)\end{array}$ & Half life \\
\hline Alpha & $5,79 \mathrm{E}-02$ & 97,88 & \\
Beta & $7,69 \mathrm{E}-04$ & 1,30 & \\
Gamma & $4,84 \mathrm{E}-04$ & 0,82 & 18.1 years \\
${ }^{244} \mathrm{Cm}$ & $2,88 \mathrm{E}-02$ & 48,60 & 87.8 years \\
${ }^{238} \mathrm{Pu}$ & $1,71 \mathrm{E}-02$ & 28,93 & 432 years \\
${ }^{241} \mathrm{Am}$ & $9,66 \mathrm{E}-03$ & 16,33 & 162 days \\
${ }^{242} \mathrm{Cm}$ & $1,73 \mathrm{E}-03$ & 2,93 & \\
Total & $5,92 \mathrm{E}-02$ & $1,00 \mathrm{E}+00$ & \\
\hline
\end{tabular}

cask is used, a maximal decay heat can be fixed at $40 \mathrm{~kW}$ for sodium cooling cask and $30 \mathrm{~kW}$ for cask with cooling by forced gas convection.

- Sodium washing of the assemblies before transportation to the reprocessing plant. After an initial cooling period in sodium, the assemblies must be drained of their sodium content and washed using various techniques (carbonation, sodium water reaction) to remove residual sodium before they can be stored under water in cooling pools. Industrial limitations on washing of the spent fuel assemblies depend on technological research, therefore a minimal and a maximal value of respectively 2.5 and $7.5 \mathrm{~kW}$ will be considered here, as done in [11].

In this study, a minimal cooling time of 5 years will be considered before sodium washing can occur and it will be supposed that reprocessing occurs directly after sodium washing has been performed. Five years of minimal cooling time is a standard hypothesis of the French scenarios studies, as it can be found in [12].

If we consider a reference MABB, loaded with $\mathrm{U}_{0.8} \mathrm{Am}_{0.2} \mathrm{O}_{2}$ with $75 \%$ of ${ }^{241} \mathrm{Am}$ and $25 \%$ of ${ }^{243} \mathrm{Am}$ and irradiated for 4100 EFPD in a SFR-V2B reactor, as discussed in [13], it is possible to analyze the contribution to decay heat and neutron source after 5 years of cooling, as it is done in Table 1 . The depletion calculations were carried out using the DARWIN code system [14]. Nearly $98 \%$ of the heat is produced through alpha-decay of heavy nuclides, with ${ }^{244} \mathrm{Cm}$ being the main heat emitter with close to $50 \%$ of the total power production, followed by ${ }^{238} \mathrm{Pu}$ and ${ }^{241} \mathrm{Am}$. Concerning neutron source, spontaneous fissions of ${ }^{244} \mathrm{Cm}$ is responsible for $96 \%$ of the total neutron source of the spent fuel [14]. ${ }^{242} \mathrm{Cm}$ has a very weak contribution to decay heat after 5 years of cooling due to its short half-life.

Considering this, it is necessary to study the formation route of these nuclei, as it is done below in equation (1). It is thus possible to split the contribution to decay heat depending on the half-lives of the nuclei considered and their parent-nuclei. Thus, the long-term decay heat will be more dictated by ${ }^{241} \mathrm{Am}$ and ${ }^{238} \mathrm{Pu}$, thus depending on the initial ${ }^{241} \mathrm{Am}$ content while neutron source and shorterterm decay heat will be depending on ${ }^{244} \mathrm{Cm}$ and thus on ${ }^{243} \mathrm{Am}$ initial content. ${ }^{241} \mathrm{Am}$ concentration will also play a role for the very-short term handling of the irradiated fuel, 


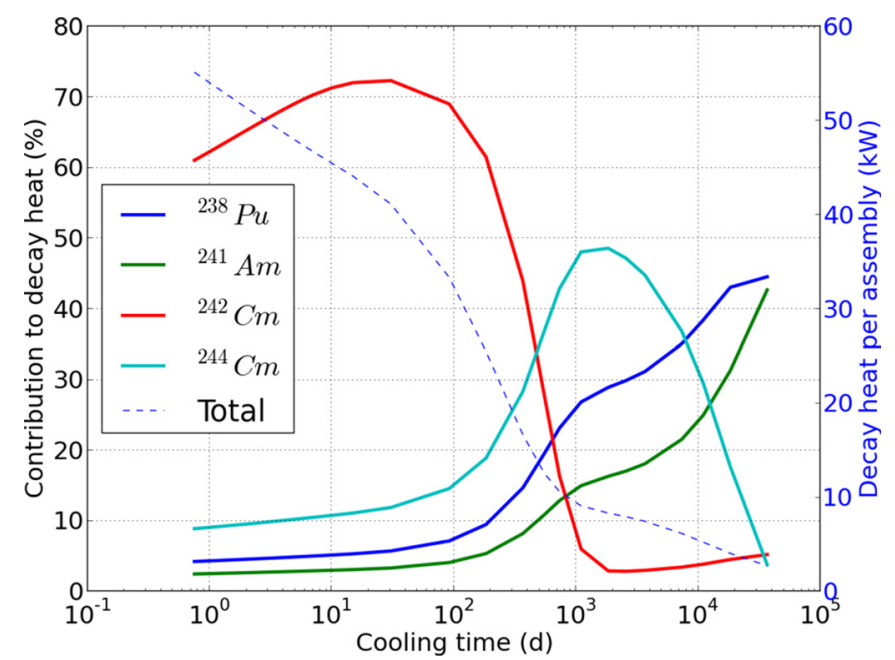

Fig. 1. Evolution of the various contributions to total decay heat versus time.

mainly due to ${ }^{242} \mathrm{Cm}$ contribution to decay heat. This is summarized in Figure 1, which plots the contribution of each nuclide to the total decay heat versus time. It can be observed that ${ }^{242} \mathrm{Cm}$ dominates short term decay heat, while ${ }^{244} \mathrm{Cm}$ contribution peaks around $5-10$ years, which is the typical time scale of a nuclear reprocessing cycle. Finally, ${ }^{238} \mathrm{Pu}$ and ${ }^{241} \mathrm{Am}$ dominate the long-term decay heat.

$$
\begin{gathered}
{ }_{95}^{241} \mathrm{Am}+{ }_{0}^{1} n \longrightarrow{ }_{95}^{242 m} \mathrm{Am} \\
{ }_{95}^{241} \mathrm{Am}+{ }_{0}^{1} n \longrightarrow{ }_{95}^{242} \mathrm{Am} \stackrel{\beta_{-, T_{1 / 2}=16 h}}{\longrightarrow}{ }_{96}^{242} \mathrm{Cm} \stackrel{{ }^{\alpha, T_{1 / 2}=162 d}}{\longrightarrow}{ }_{94}^{238} \mathrm{Pu}
\end{gathered}
$$$$
{ }_{95}^{243} A m+{ }_{0}^{1} n \longrightarrow{ }_{95}^{244} A m \stackrel{\beta-, T_{1 / 2}=10 h}{\longrightarrow} \quad{ }_{96}^{244} \mathrm{Cm} .
$$

Going back to the reprocessing limits considered above, it can be observed that depending on the current reprocessing limit, the main contributor to the decay heat will not be same. Consequently, the cooling time of the assemblies will depend both on the americium isotopic vector loaded in the blankets and on the reprocessing limit, as shown in Figure 2. In this figure, the cooling time was plotted with regards to the fraction of ${ }^{241} \mathrm{Am}$ in the americium irradiated for various decay heat limit.

It is observed that the slope of the cooling time evolution changes of sign depending on the limit considered. For high decay limit, the cooling time decreases with the ${ }^{241} \mathrm{Am}$ fraction as the short-term decay heat depends on ${ }^{244} \mathrm{Cm}$ production. Consequently, the decay of ${ }^{244} \mathrm{Cm}$ only is sufficient to reach an acceptable decay heat, and any decrease in the ${ }^{243} \mathrm{Am}$ content will decrease the ${ }^{244} \mathrm{Cm}$ production. On the other hand, for low limits, the cooling time increase with the ${ }^{241} \mathrm{Am}$ fraction. Indeed, in this case, the decay of ${ }^{244} \mathrm{Cm}$ is not sufficient to achieve a final decay heat lower than the limit, and it is necessary to wait for ${ }^{241} \mathrm{Am}$ and ${ }^{238} \mathrm{Pu}$ decay to reach the limit, which requires a much longer time. Consequently, an increase in the ${ }^{241} \mathrm{Am}$ fraction will increase the cooling time for such cases.

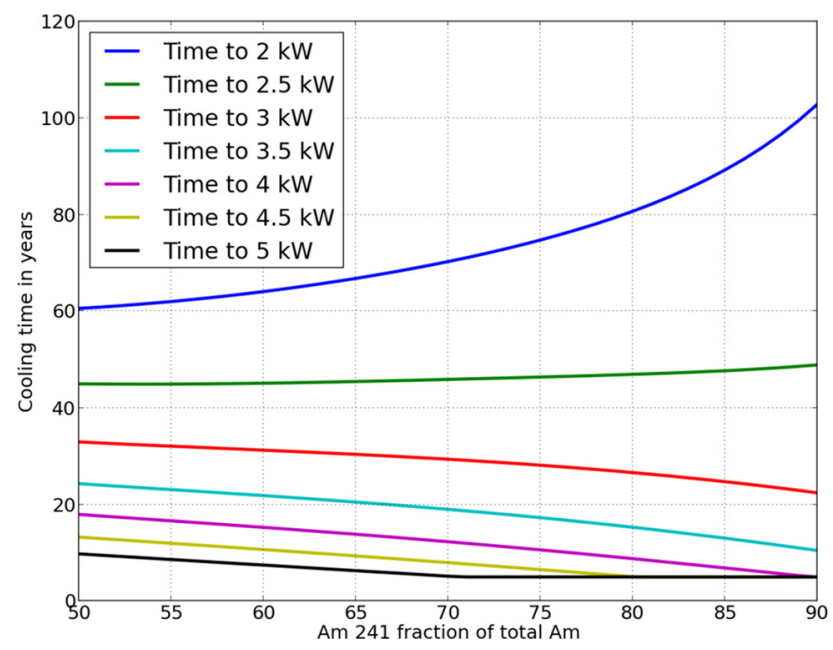

Fig. 2. Cooling time for various limiting values depending on the fraction of ${ }^{241} \mathrm{Am}$ in the americium isotopic vector. A minimal cooling time of 5 years was considered.

Considering this, it is postulated here that depending on the industrial constraint for reprocessing and on the availability of various americium fluxes in the fuel cycle, an optimization can be carried out to minimize the cooling time of the irradiated targets at any given time.

\section{Analysis of the available americium feeds}

The americium isotopic vector present in the fuel depends on various parameters which are:

- The initial fissile content of the fuel : an UOX fuel will generate more ${ }^{241} \mathrm{Am}$ than ${ }^{243} \mathrm{Am}$ compared to a MOX fuel.

- The neutron spectrum: ${ }^{243} \mathrm{Am}$ production will be higher in a thermal spectrum than in a fast spectrum due to increased captures on ${ }^{242} \mathrm{Pu}$.

- The fuel burn up : a higher burnup will increase the production of ${ }^{243} \mathrm{Am}$ due to increased captures on ${ }^{242} \mathrm{Pu}$.

- The plutonium isotopic vector used in the fuel: a higher quality of the plutonium will limit the production of ${ }^{243} \mathrm{Am}$, where the quality of the plutonium is defined by its content in "good" fissile elements, e.g. ${ }^{239} \mathrm{Pu}$ and ${ }^{241} \mathrm{Pu}$. The plutonium isotopic vectors used in this study are given in Table 2.

- The spent fuel cooling time before reprocessing: once reprocessing is carried out, the production of ${ }^{241} \mathrm{Am}$ from the decay of ${ }^{241} \mathrm{Pu}$ is stopped. A short cooling time will limit the amount of ${ }^{241} \mathrm{Am}$ produced and then increase the ${ }^{243} \mathrm{Am}$ content in the americium, while a longer cooling time will increase the content in ${ }^{241} \mathrm{Am}$.

An analysis of the various isotopic vectors that can be obtained is shown below in Table 3. At unloading, the ratio of ${ }^{241} \mathrm{Am}$ to ${ }^{243} \mathrm{Am}$ is found to be between $78 \%$ and $51 \%$ depending on the core considered, while after 5 years of cooling, which is the minimal time of cooling generally considered, this ratio oscillates between 85 and $65 \%$. Considering a $2 \mathrm{~kW}$ reprocessing limit in Figure 2, this amounts to a difference of 23 years in the cooling time, 
Table 2. High and low quality plutonium content isotopic vector used here.

\begin{tabular}{lllllll}
\hline & ${ }^{238} \mathrm{Pu}$ & ${ }^{239} \mathrm{Pu}$ & ${ }^{240} \mathrm{Pu}$ & ${ }^{241} \mathrm{Pu}$ & ${ }^{242} \mathrm{Pu}$ & ${ }^{241} \mathrm{Am}$ \\
\hline Low quality $\mathrm{Pu}$ & 3,57 & 47,4 & 29,7 & 8,2 & 10,4 & 0,78 \\
High quality $\mathrm{Pu}$ & 0,61 & 62,9 & 30,5 & 2,5 & 3,1 & 0,45 \\
\hline
\end{tabular}

Table 3. Americium isotopic content for various cases depending on the reactor type and burn-up

\begin{tabular}{llllll}
\hline Reactor type & Isotopic content & Unloading & $\begin{array}{l}5 \text { years of } \\
\text { cooling }\end{array}$ & $\begin{array}{l}7 \text { years of } \\
\text { cooling }\end{array}$ & Cooling > 100 years \\
\hline \multirow{2}{*}{ 900 MWe UOX PWR, } & Am 241 (kg/year) & 4,4 & 9,8 & 11,7 & 37,1 \\
33 GWd/t [15] & Am 243 (kg/year) & 2,2 & 2,2 & 2,2 & 2,2 \\
& Ratio Am 241/Am (\%) & 67 & 82 & 84 & 94 \\
900 MWe MOX PWR, & Am 241 (kg/year) & 14,4 & 23,1 & 26,0 & 55,1 \\
43,5 GWd/t [15] & Am 243 (kg/year) & 4,0 & 4,0 & 4,0 & 4,0 \\
& Ratio Am 241/Am (\%) & 78,3 & 85,2 & 86,7 & 93,2 \\
1450 MWe Low quality & Am 241 (kg/year) & 30,4 & 53,6 & 61,4 & 140,3 \\
Pu SFR, 100 GWd/t [16] & Am 243 (kg/year) & 29,2 & 29,2 & 29,2 & 29,2 \\
& Ratio Am 241/Am (\%) & 51,0 & 64,7 & 67,8 & 82,8 \\
1450 MWe High quality & Am 241 (kg/year) & 16,2 & 33,1 & 38,6 & 96,1 \\
Pu SFR, 100 GWd/t [16] & Am 243 (kg/year) & 8,4 & 8,4 & 8,4 & 8,4 \\
& Ratio Am 241/Am (\%) & 65,9 & 79,8 & 82,2 & 92,0 \\
\hline
\end{tabular}

which is not negligible. For a $2.5 \mathrm{~kW}$ limit, the difference is only of 2 years. If we consider a very long cooling time during which all the ${ }^{241} \mathrm{Pu}$ decays, the final ratio varies between 83 and $94 \%$, still leading to a significant difference for low reprocessing limit.

We will consider here heterogeneous transmutation of americium for three cases, in which either the americium from various sources will be mixed or a specific strategy will be used depending on the isotopic vector. For each case, the impact of the decay heat limit will be analyzed. The radial blankets will be irradiated in a SFR V2B fast reactor with a design corresponding to [16] for 4100 EFPD in the form of $\mathrm{U}_{0.8} \mathrm{Am}_{0.2} \mathrm{O}_{2}$. The cases chosen represent situations where different americium flows are available:

- One where half of the fleet is composed of PWR with UOX fuel and the other half made of PWR with MOX fuel (transition between UOX and MOX fuels PWR).

- One where half of the fleet is composed of PWR with MOX fuel and the other half of SFR with low quality plutonium (transition between MOX fuel PWR and SFR).

- One where half of the fleet is composed of SFR with low quality plutonium and the other half of SFR with high quality plutonium (closure of the fuel cycle with fast reactors).

The impact on short term decay heat and neutron source will also be analyzed in these calculations. For each case, the total inventory in the fuel cycle will be analyzed by considering the mass unloaded at the end of irradiation, its cooling time, and the mass not transmuted. $2413 \mathrm{~kg}$ of americium can be loaded in the blankets for the configuration considered. The americium isotopic vector will be characterized by its ${ }^{241} \mathrm{Am}$ content over the total americium, the remaining fraction being ${ }^{243} \mathrm{Am}$.

\section{Results}

\subsection{Case 1: PWR UOX and MOX}

In this case, the americium vector between both cases is relatively similar as it is mainly dependent on the neutron spectrum in thermal reactors, with the use of MOX fuel simply increasing the total production of americium. Consequently, no specific calculations are required to draw a conclusion here. To avoid prohibitively long cooling times, either the reprocessing limit must be increased or the time before reprocessing and unloading must be shortened to prevent production of ${ }^{241} \mathrm{Am}$.

\subsection{Case 2: PWR MOX and SFR MOX with low quality plutonium}

In this case, the americium isotopic vector between both cases is very dissimilar, with a significantly higher production of ${ }^{243} \mathrm{Am}$ in the SFR case due to the high content in ${ }^{242} \mathrm{Pu}$ in the low quality plutonium. Three approaches can be considered here:

- transmute first the americium from the MOX reactor and then the americium from the SFR, which will have more time to decay;

- transmute first the americium from the SFR, and then the americium from the MOX; 
Table 4. Cooling time and americium content for the three strategies studied here

\begin{tabular}{|c|c|c|c|c|c|c|}
\hline \multirow{6}{*}{$\begin{array}{l}\text { MOX then } \\
\text { SFR }\end{array}$} & \multicolumn{6}{|c|}{ First irradiation } \\
\hline & $\begin{array}{l}\text { Loaded mass } \\
\text { MOX vector }(\mathrm{kg})\end{array}$ & Am41 content $(\%)$ & $\begin{array}{l}\text { Unloaded mass } \\
\text { of } A m(\mathrm{~kg})\end{array}$ & $\begin{array}{l}\text { Cooling time } \\
\text { to } 7.5 \mathrm{~kW}(\mathrm{y})\end{array}$ & $\begin{array}{l}\text { Cooling time } \\
\text { to } 5 \mathrm{~kW}(\mathrm{y})\end{array}$ & $\begin{array}{l}\text { Cooling time } \\
\text { to } 2.5 \mathrm{~kW}(\mathrm{y})\end{array}$ \\
\hline & 2413 & 85.2 & 1461 & 5 & 28.45 & 160 \\
\hline & \multicolumn{6}{|c|}{ Second irradiation } \\
\hline & $\begin{array}{l}\text { Loaded mass SFR } \\
\text { vector }(\mathrm{kg})\end{array}$ & Am41 content $(\%)$ & $\begin{array}{l}\text { Unloaded mass } \\
\text { of } A m(\mathrm{~kg})\end{array}$ & $\begin{array}{l}\text { Cooling time } \\
\text { to } 7.5 \mathrm{~kW}(\mathrm{y})\end{array}$ & $\begin{array}{l}\text { Cooling time } \\
\text { to } 5 \mathrm{~kW}(\mathrm{y})\end{array}$ & $\begin{array}{l}\text { Cooling time } \\
\text { to } 2.5 \mathrm{~kW}(\mathrm{y})\end{array}$ \\
\hline & 2413 & 75 & 1470 & 8.9 & 32.5 & 118 \\
\hline \multirow{5}{*}{$\begin{array}{l}\text { SFR then } \\
\text { MOX }\end{array}$} & \multicolumn{6}{|c|}{ First irradiation } \\
\hline & $\begin{array}{l}\text { Loaded mass SFR } \\
\text { vector }(\mathrm{kg})\end{array}$ & Am41 content $(\%)$ & $\begin{array}{l}\text { Unloaded mass } \\
\text { of } \mathrm{Am}(\mathrm{kg})\end{array}$ & $\begin{array}{l}\text { Cooling time } \\
\text { to } 7.5 \mathrm{~kW}(\mathrm{y})\end{array}$ & $\begin{array}{l}\text { Cooling time } \\
\text { to } 5 \mathrm{~kW}(\mathrm{y})\end{array}$ & $\begin{array}{l}\text { Cooling time } \\
\text { to } 2.5 \mathrm{~kW}(\mathrm{y})\end{array}$ \\
\hline & 2413 & 64.7 & 1480 & 12.4 & 34.9 & 98 \\
\hline & \multicolumn{6}{|c|}{ Second irradiation } \\
\hline & $\begin{array}{l}\text { Loaded mass } \\
\text { MOX vector }(\mathrm{kg})\end{array}$ & Am41 content $(\%)$ & $\begin{array}{l}\text { Unloaded mass } \\
\text { of Am }(\mathrm{kg})\end{array}$ & $\begin{array}{l}\text { Cooling time } \\
\text { to } 7.5 \mathrm{~kW}(\mathrm{y})\end{array}$ & $\begin{array}{l}\text { Cooling time } \\
\text { to } 5 \mathrm{~kW}(\mathrm{y})\end{array}$ & $\begin{array}{l}\text { Cooling time } \\
\text { to } 2.5 \mathrm{~kW}(\mathrm{y})\end{array}$ \\
\hline 2413 & 90 & 1456 & 5 & 26 & 202 & \\
\hline \multirow{6}{*}{ MIX } & \multicolumn{6}{|c|}{ First irradiation } \\
\hline & $\begin{array}{l}\text { Loaded mass MIX } \\
\text { vector }(\mathrm{kg})\end{array}$ & Am41 content $(\%)$ & $\begin{array}{l}\text { Unloaded mass } \\
\text { of } A m(\mathrm{~kg})\end{array}$ & $\begin{array}{l}\text { Cooling time } \\
\text { to } 7.5 \mathrm{~kW}(\mathrm{y})\end{array}$ & $\begin{array}{l}\text { Cooling time } \\
\text { to } 5 \mathrm{~kW}(\mathrm{y})\end{array}$ & $\begin{array}{l}\text { Cooling time } \\
\text { to } 2.5 \mathrm{~kW}(\mathrm{y})\end{array}$ \\
\hline & 2413 & 69.7 & 1476 & 10.7 & 33.9 & 106.7 \\
\hline & \multicolumn{6}{|c|}{ Second irradiation } \\
\hline & $\begin{array}{l}\text { Loaded mass MIX } \\
\text { vector }(\mathrm{kg})\end{array}$ & Am41 content $(\%)$ & $\begin{array}{l}\text { Unloaded mass } \\
\text { of Am }(\mathrm{kg})\end{array}$ & $\begin{array}{l}\text { Cooling time } \\
\text { to } 7.5 \mathrm{~kW}(\mathrm{y})\end{array}$ & $\begin{array}{l}\text { Cooling time } \\
\text { to } 5 \mathrm{~kW}(\mathrm{y})\end{array}$ & $\begin{array}{l}\text { Cooling time } \\
\text { to } 2.5 \mathrm{~kW}(\mathrm{y})\end{array}$ \\
\hline & 2413 & 78.8 & 1467 & 7.5 & 31.2 & 130.1 \\
\hline
\end{tabular}

- mix the two vectors and transmute the resulting isotopic vector.

We considered here that a first loading of americium was irradiated while the equivalent mass was stored awaiting reprocessing. At the end of the 4100 days of irradiation, the second mass was loaded in the core while the first was stored until the limiting decay heat was obtained. The corresponding cooling times are shown in Table 4. A wide variation range depending on the isotopic vector considered can be observed, with differences increasing with the reprocessing limit. It can also be observed that the americium consumption only slightly depends on the isotopic vector, with the consumption increasing with the ${ }^{243} \mathrm{Am}$ content.

Considering the results shown in Table 4, it is interesting to plot the total quantity of americium corresponding to the initial mass of $4826 \mathrm{~kg}$ to be loaded in the blankets. This is done in Figure 3, which shows the evolution of the americium in the fuel cycle depending on the strategy and the reprocessing limit. When the mass reaches $0 \mathrm{~kg}$, the total of the remaining americium loading has reached decay heat value lower than the limit and can be reprocessed. It can be observed that the reprocessing of the SFR one followed by the MOX one leads to a faster total cooling for limits of 7.5 and $5 \mathrm{~kW}$. On the other hand, this approach yields the worst result for a $2.5 \mathrm{~kW}$ limit, with a mixing strategy yielding the best results.
Indeed, for high decay limit, it appears more interesting to reprocess the americium feed with the highest ${ }^{243} \mathrm{Am}$ content first so that it decays during the irradiation of the second feed, than starting with the feed with the lowest cooling time and then going one with the second one. For low decay heat level, it appears more interesting to homogenize the two feeds so as to limit the total content in ${ }^{241} \mathrm{Am}$ in both cases.

\subsection{Case 3: SFR MOX with low and high quality plutonium}

This case is slightly similar to the previous one, with the high quality feed with a low ${ }^{243} \mathrm{Am}$ production replacing the MOX feed, with the main difference being that the two sources are producing the same mass, which means the mixing of the two vectors will yield different isotopic vectors. The results are shown in Table 5, with the evolution of the mass in the fuel cycle shown in Figure 4. The reprocessing of low quality and then of the high quality is optimal in the case of $7.5 \mathrm{~kW}$ limit, as the low quality vector has the time to cool down during the irradiation of the high quality vector, which itself has a short cooling time. For lower reprocessing limit, it appears that reprocessing first the high quality feed id optimal, as it limits the relative content of ${ }^{241} \mathrm{Am}$ in the irradiated americium, and thus the long term cooling time. 


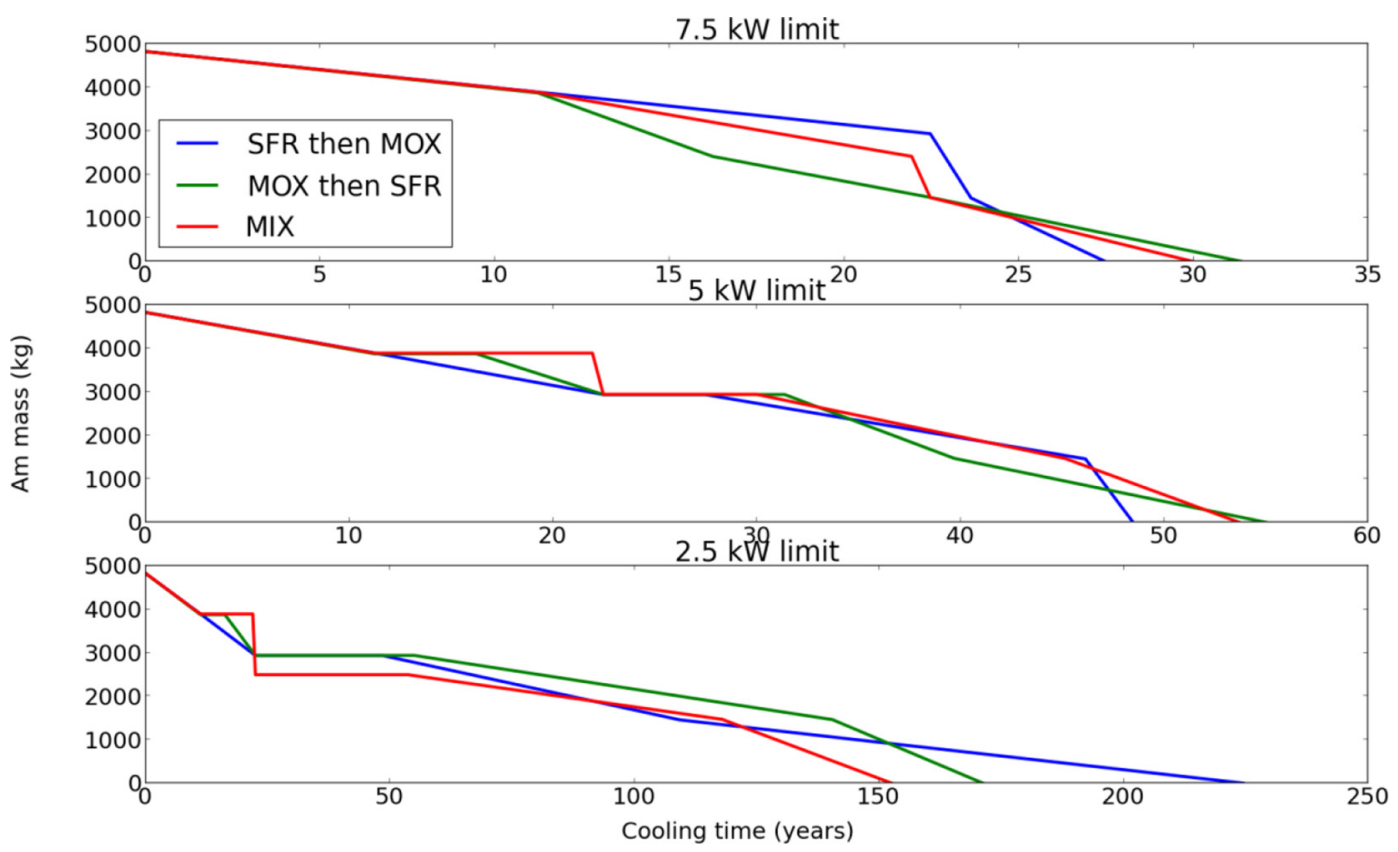

Fig. 3. Evolution of the americium in the fuel cycle depending on the strategy considered and on the reprocessing limit for coupled scenarios with MOX reactors and SFR.

Table 5. Cooling time and americium content for the three strategies with sodium fast reactor studied here.

\begin{tabular}{|c|c|c|c|c|c|c|}
\hline \multirow{6}{*}{$\begin{array}{l}\text { Low then } \\
\text { high quality }\end{array}$} & \multicolumn{6}{|c|}{ First irradiation } \\
\hline & $\begin{array}{l}\text { Loaded mass } \\
\text { Low quality } \\
\text { vector }(\mathrm{kg})\end{array}$ & $\begin{array}{l}\text { Am41 } \\
\text { content (\%) }\end{array}$ & $\begin{array}{l}\text { Unloaded mass } \\
\text { of Am }(\mathrm{kg})\end{array}$ & $\begin{array}{l}\text { Cooling time } \\
\text { to } 7.5 \mathrm{~kW}(\mathrm{y})\end{array}$ & $\begin{array}{l}\text { Cooling time } \\
\text { to } 5 \mathrm{~kW}(\mathrm{y})\end{array}$ & $\begin{array}{l}\text { Cooling time } \\
\text { to } 2.5 \mathrm{~kW}(\mathrm{y})\end{array}$ \\
\hline & 2413 & 64.7 & 1480 & 12.4 & 34.9 & 98 \\
\hline & \multicolumn{6}{|c|}{ Second irradiation } \\
\hline & $\begin{array}{l}\text { Loaded mass } \\
\text { high quality } \\
\text { vector }(\mathrm{kg})\end{array}$ & $\begin{array}{l}\text { Am41 } \\
\text { content (\%) }\end{array}$ & $\begin{array}{l}\text { Unloaded mass } \\
\text { of Am }(\mathrm{kg})\end{array}$ & $\begin{array}{l}\text { Cooling time } \\
\text { to } 7.5 \mathrm{~kW}(\mathrm{y})\end{array}$ & $\begin{array}{l}\text { Cooling time } \\
\text { to } 5 \mathrm{~kW}(\mathrm{y})\end{array}$ & $\begin{array}{l}\text { Cooling time } \\
\text { to } 2.5 \mathrm{~kW}(\mathrm{y})\end{array}$ \\
\hline & 2413 & 90.8 & 1456 & 5 & 25.4 & 212 \\
\hline \multirow{6}{*}{$\begin{array}{l}\text { High then } \\
\text { low quality }\end{array}$} & \multicolumn{6}{|c|}{ First irradiation } \\
\hline & $\begin{array}{l}\text { Loaded mass } \\
\text { high quality } \\
\text { vector }(\mathrm{kg})\end{array}$ & $\begin{array}{l}\text { Am41 } \\
\text { content (\%) }\end{array}$ & $\begin{array}{l}\text { Unloaded mass } \\
\text { of Am }(\mathrm{kg})\end{array}$ & $\begin{array}{l}\text { Cooling time } \\
\text { to } 7.5 \mathrm{~kW}(\mathrm{y})\end{array}$ & $\begin{array}{l}\text { Cooling time } \\
\text { to } 5 \mathrm{~kW}(\mathrm{y})\end{array}$ & $\begin{array}{l}\text { Cooling time } \\
\text { to } 2.5 \mathrm{~kW}(\mathrm{y})\end{array}$ \\
\hline & 2413 & 79.8 & 1466 & 7.1 & 30.8 & 133.6 \\
\hline & \multicolumn{6}{|c|}{ Second irradiation } \\
\hline & $\begin{array}{l}\text { Loaded mass } \\
\text { Low quality } \\
\text { vector }(\mathrm{kg})\end{array}$ & $\begin{array}{l}\text { Am41 } \\
\text { content (\%) }\end{array}$ & $\begin{array}{l}\text { Unloaded mass } \\
\text { of Am (kg) }\end{array}$ & $\begin{array}{l}\text { Cooling time } \\
\text { to } 7.5 \mathrm{~kW}(\mathrm{y})\end{array}$ & $\begin{array}{l}\text { Cooling time } \\
\text { to } 5 \mathrm{~kW}(\mathrm{y})\end{array}$ & $\begin{array}{l}\text { Cooling time } \\
\text { to } 2.5 \mathrm{~kW}(\mathrm{y})\end{array}$ \\
\hline & 2413 & 75.5 & 1470 & 8.7 & 32.2 & 119.7 \\
\hline \multirow{6}{*}{ MIX } & \multicolumn{6}{|c|}{ First irradiation } \\
\hline & $\begin{array}{l}\text { Loaded mass } \\
\text { MIX vector }(\mathrm{kg})\end{array}$ & $\begin{array}{l}\text { Am41 } \\
\text { content (\%) }\end{array}$ & $\begin{array}{l}\text { Unloaded mass } \\
\text { of Am }(\mathrm{kg})\end{array}$ & $\begin{array}{l}\text { Cooling time } \\
\text { to } 7.5 \mathrm{~kW}(\mathrm{y})\end{array}$ & $\begin{array}{l}\text { Cooling time } \\
\text { to } 5 \mathrm{~kW}(\mathrm{y})\end{array}$ & $\begin{array}{l}\text { Cooling time } \\
\text { to } 2.5 \mathrm{~kW}(\mathrm{y})\end{array}$ \\
\hline & 2413 & 72.3 & 1473 & 9.8 & 33.2 & 112.1 \\
\hline & \multicolumn{6}{|c|}{ Second irradiation } \\
\hline & $\begin{array}{l}\text { Loaded mass } \\
\text { MIX vector }(\mathrm{kg})\end{array}$ & $\begin{array}{l}\text { Am41 } \\
\text { content (\%) }\end{array}$ & $\begin{array}{l}\text { Unloaded mass } \\
\text { of Am }(\mathrm{kg})\end{array}$ & $\begin{array}{l}\text { Cooling time } \\
\text { to } 7.5 \mathrm{~kW}(\mathrm{y})\end{array}$ & $\begin{array}{l}\text { Cooling time } \\
\text { to } 5 \mathrm{~kW}(\mathrm{y})\end{array}$ & $\begin{array}{l}\text { Cooling time } \\
\text { to } 2.5 \mathrm{~kW}(\mathrm{y})\end{array}$ \\
\hline & 2413 & 83.1 & 1463 & 5.9 & 29.6 & 149 \\
\hline
\end{tabular}




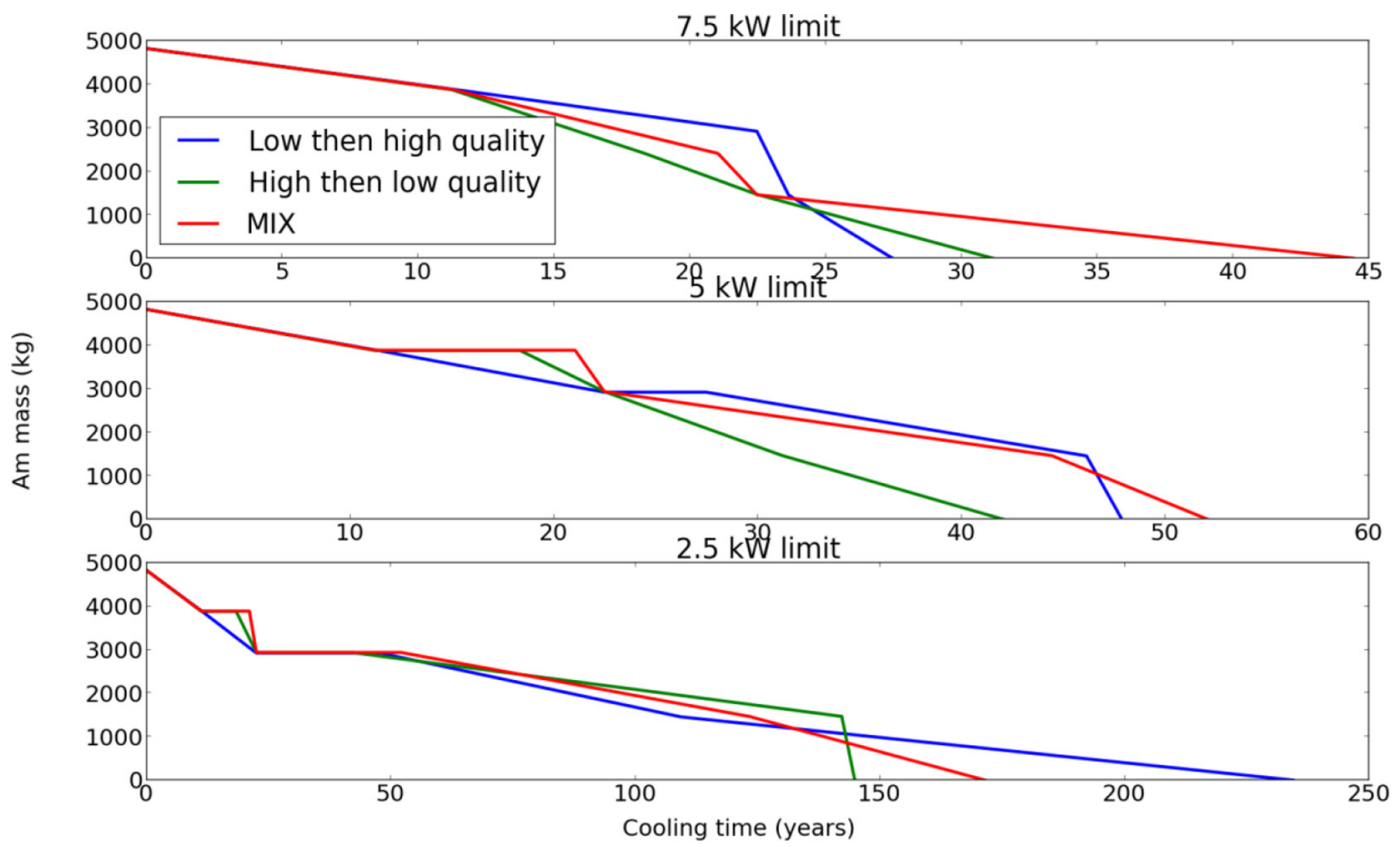

Fig 4. Evolution of the americium in the fuel cycle depending on the strategy considered and on the reprocessing limit for coupled scenarios with various $\mathrm{Pu}$ qualities in SFR.

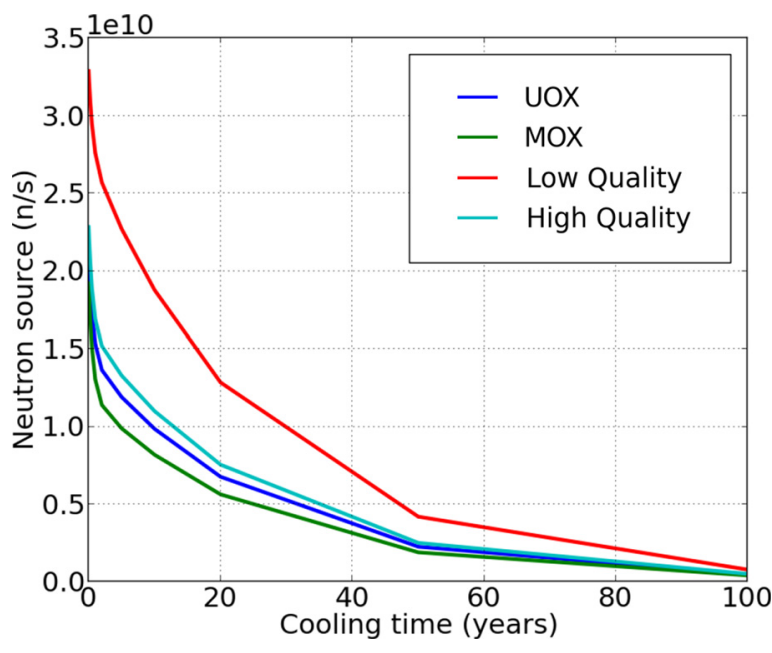

Fig. 5. Comparison of the neutron source per assembly for each of the initial americium feed.

As a conclusion, it appears that no significant gain can be achieved by choosing PWR UOX or MOX americium isotopic vector for reprocessing. However, it was shown that for high decay limit, reprocessing and transmuting first the feed with the highest ${ }^{243} \mathrm{Am}$ fraction is optimal, while for lower decay heat limit, it was more interesting to homogenize the americium feed so as to limit the ${ }^{241} \mathrm{Am}$ content in the irradiated americium. In the next part, the impacts on the short term decay heat and on the neutron source of both strategies will be analyzed.

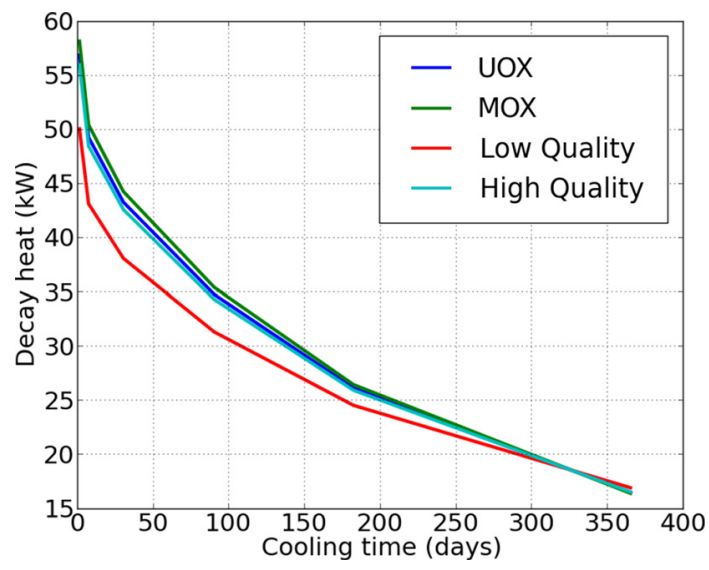

Fig. 6. Comparison of the short term decay heat per assembly for each of the initial americium feed.

\section{Neutron source and short term decay analysis}

Reprocessing and irradiating first the americium feed with the highest ${ }^{243} \mathrm{Am}$ content has a negative impact on the neutron source of the irradiated targets. On the other hand, waiting for ${ }^{241} \mathrm{Pu}$ decay dilutes the ${ }^{243} \mathrm{Am}$ and thus decreases the amount of ${ }^{244} \mathrm{Cm}$ produced during irradiation. As no specific industrial limitations exists on the 
maximal neutron source allowed for handling irradiated targets with a high neutron source, no criterion can be defined with regards to their acceptance. Additionally, comparison of the neutron source is pertinent only for relatively short cooling time corresponding to a $7.5 \mathrm{~kW}$ limit, as for longer cooling times, most of the ${ }^{244} \mathrm{Cm}$ will have decayed. The neutron source of each of the initial americium feed is shown in Figure 5. It can be observed that transmuting first the feed with the highest ${ }^{243} \mathrm{Am}$ content will have significant impact on the neutron source of the irradiated assemblies, which is twice as high in the low quality plutonium case than in the other cases.

Regarding short term decay heat of the irradiated assemblies, the conclusion is reversed, as this parameter depends on the ${ }^{241} \mathrm{Am}$ fraction. This can be observed in Figure 6 . The low quality plutonium feed has a significantly lower short term decay heat than the other feeds. However, the decrease in the handling time for a 40 or a $30 \mathrm{~kW}$ limit is limited to around 30 days which is not significant compared to the entire fuel cycle.

\section{Conclusions}

The impact of the choice of the americium feed in the reprocessing of the americium loaded targets for heterogeneous minor actinides transmutation has been analyzed in this paper. It has been shown that the short and long term decay heat of the targets was governed by the ${ }^{241} \mathrm{Am}$ content while the mid term decay heat and neutron source were dependent on the ${ }^{243} \mathrm{Am}$ content. It was shown that, for high decay heat limit, reprocessing first the feed with a high ${ }^{243} \mathrm{Am}$ content was more interesting to limit the total cooling time of the targets, while if a lower reprocessing limit was considered, it was more interesting to reprocess first the feed rich in ${ }^{241} \mathrm{Am}$. Adequate choice of transmutation and reprocessing orders appears a potential solution to limit the cooling time of minor actinides bearing blankets by more than 10 years depending on the reprocessing limit considered. It is planned to consolidate these preliminary results by using a complete analysis based on industrial electronuclear scenarios.

\section{References}

1. GIF, Annual Report, 2013
2. M. Salvatores, Nuclear fuel cycle strategies including partitioning and transmutation, Nucl. Eng. Des. 235, 805 (2005)

3. C. Chabert, D. Warin, J. Milot, A. Saturnin A. Leudet, Impact of minor actinide transmutation options on interim storage and geological disposal, in IEMPT, Prague, 2012

4. C. Chabert, C. Coquelet-Pascal, A. Saturnin, G. Mathonniere, B. Boullis, D. Warin et al. Technical and economic assessment of different options for minor actinides transmutation: the French case, in GLOBAL 2011, Tokyo (2011)

5. NEA, Homogeneous versus heterogeneous recycling of transuranics in fast nuclear reactors (NEA, Paris, 2012)

6. C. De Saint Jean, Americium once-through of moderated targets in a CAPRA core, in Seminar Int. CAPRA conf. Karlsruhe, 1998

7. G. Palmiotti, M. Salvatores, M. Assawaroongreungchot, Impact of the core minor actinide content on fast reactor reactivity coefficients, J. Nucl. Sci. Technol. 48, 628 (2011)

8. F. Lebreton, D. Prieur, A. Jankowiak, M. Tribet, C. Leorier, T. Delahaye, et al. Fabrication and characterization of americium, neptunium and curium bearing MOX fuels obtained by powder metallurgy process, J. Nucl. Mater. 420, 213 (2012)

9. C. de Saint Jean, J. Tommasi, F. Varaine, N. Schmidt, D. Plancq, Americium and curium heterogeneous transmutation in moderated $S / A$ in the framework of CNE scenarios studies, in GLOBAL, Paris, 2001

10. S. Pillon, J. Somers, S. Grandjean, J. Lacquement. Aspects of fabrication of curium-based fuels and targets, J. Nucl. Mater. 320, 36 (2003)

11. C. Chabert et al. Considerations on the industrial feasibility of scenarios with the progressive deployment of $\mathrm{Pu}$ multirecycling in SFRs in the french nuclear power fleet, in GLOBAL, Paris, 2015

12. C. Coquelet-Pascal, M. Meyer, R. Girieud, M. Tiphine, R. Eschbach, C. Chabert et al. Scenarios for fast reactors deployment with plutonium recycling, in Fast Reactors, Paris, 2013

13. L. Buiron, Heterogeneous minor actinides transmutation on a $\mathrm{UO} 2$ blanket and on $(\mathrm{U}, \mathrm{Pu}) \mathrm{O}_{2}$ fuel in sodium-cooled fast reactor. Assessment of core performances, in GLOBAL, Paris, 2009

14. A. Tsilanizara, C. Diop, B. Nimal, M. Detoc, L. Luneville, M. Chiron et al. DARWIN: An Evolution Code System for a Large Range, J. Nucl. Sci. Technol. 1, 845 (2000)

15. P. Reuss, Précis de neutronique (EDP Sciences, Paris, 2003)

16. P. Sciora, L. Buiron, G. Rimpault, F. Varaine, A break even oxide fuel core for an innovative French sodium-cooled fast reactor : neutronic studies results, in GLOBAL, Paris, 2009

Cite this article as: Timothée Kooyman, Laurent Buiron, Gerald Rimpault, On the influence of the americium isotopic vector on the cooling time of minor actinides bearing blankets in fast reactors, EPJ Nuclear Sci. Technol. 4, 11 (2018) 